\title{
Associations of ERCC4 rs1800067 Polymorphism with Cancer Risk: an Updated Meta-analysis
}

\author{
Quan Yuan, Jing-Wei Liu, Cheng-Zhong Xing, Yuan Yuan*
}

\begin{abstract}
Background: Results from previous studies concerning the association of $E R C C 4$ rs1800067 polymorphism with risk of cancer were inconsistent. To explore the exact relation with susceptibility, we conducted the present meta-analysis. Materials and Methods: Literature of electronic databases including PubMed, Web of Science, EMBASE, Wanfang and Chinese National Knowledge Infrastructure (CNKI) were systematically searched. ORs and their $95 \%$ CIs were used to assess the strength of associations between ERCC4 polymorphism and cancer risk. Results: There was no significant association between ERCC4 rs1800067 AA or AG genotypes and overall risk of cancer (AA vs. GG: $O R=0.998,95 \% C I=0.670-1.486, P=0.992$; $A G$ vs. $G G$ : $O R=0.970,95 \% C I=0.888$ 1.061, $P=0.508$ ). A dominant genetic model also did not demonstrate significant association of (AA+AG) genotype carriers with altered risk of overall cancer $(\mathrm{OR}=0.985,95 \% \mathrm{CI}=0.909-1.068, P=0.719)$. In addition, no significant association was observed between A allele of ERCC4 $\mathrm{rs1800067} \mathrm{A} / \mathrm{G}$ polymorphism and altered cancer risk compared with $G$ allele $(O R=0.952,95 \% C I=0.851-1.063, P=0.381)$. Subgroup analysis suggested that AA genotype carriers were significantly associated with decreased risk of glioma compared with wild-type GG genotype individuals $(\mathrm{OR}=\mathbf{0 . 5 2 3}, \mathbf{9 5 \%} \mathrm{CI}=\mathbf{0 . 2 7 5 - 0 . 9 9 3 ,} P=\mathbf{0 . 0 4 8})$. For subgroup of lung cancer, $A$ allele of $E R C C 4 \mathrm{rs} 1800067 \mathrm{~A} / \mathrm{G}$ polymorphism was significantly associated with decreased risk of lung cancer compared with $\mathbf{G}$ allele $(\mathrm{OR}=\mathbf{0 . 8 0 6}, 95 \% \mathrm{CI}=\mathbf{0 . 6 9 7 - 0 . 9 3 1}, \boldsymbol{P}=\mathbf{0 . 0 0 3})$. Conclusions: This meta-analysis indicated that $E R C C 4$ $\operatorname{rs} 1800067 \mathrm{~A} / \mathrm{G}$ polymorphism might not be associated with risk of overall cancer. However, individuals with the AA genotype were associated with significantly reduced risk of glioma compared with wild-type GG genotype; The A allele was associated with significantly reduced risk of lung cancer compared with $G$ allele. Future largescale studies performed in multiple populations are warranted to confirm our results.
\end{abstract}

Keywords: ERCC4 - polymorphism - cancer - meta-analysis

Asian Pac J Cancer Prev, 15 (18), 7639-7644

\section{Introduction}

DNA repair system play a pivotal role in maintaining normal functions of cells (Lindahl and Wood, 1999). In recent years, emerging numbers of studies investigated the relation of DNA damage and repair with the occurrence of cancer. Humans cells employ multiple and specific repair pathways such as nucleotide excision repair (NER) and base excision repair (BER) to repair DNA damage. NER is a versatile system that monitors and repairs a variety of DNA damage, including UV-induced cyclobutane pyrimidine dimers, bulky adducts and DNA crosslinks (de Laat et al., 1999). Excessive DNA damage may give rise to cancer, therefore NER exert important effect in the initiation and development of cancer.

NER system is composed of multiple steps including damage recognition, damage demarcation and unwinding, damage incision and new strand ligation (Friedberg, 2001). Each step requires corresponding functional proteins, and various factors are involved in this complex and precise process, including ERCC1, ERCC2, ERCC3, ERCC4, ERCC5, XPA, XPC, DDB2 and so on. Excision repair cross-complementation group 4 (ERCC4), alternatively known as XPF, is an important member of NER system. The XPF-ERCC1 heterodimer is responsible for the 5' incision of the dual incision process in the NER pathway (Fagbemi et al., 2011). Besides, the XPF-ERCC1 heterodimer also exerts an important role in maintaining telomere stability and repairing interstrand cross-links (Niedernhofer et al., 2004).

Studies suggested that ERCC4 gene possessed hundreds of single nucleotide polymorphisms (SNPs), some of which have been linked to the susceptibilities to bladder cancer, lung cancer, breast cancer, colorectal 
cancer and so on. ERCC4 rs1800067 A/G polymorphism could cause the change from Arg to Gln, which may lead to the alternation of ERCC4 protein function and thus influencing the role of NER in carcinogenesis. A number of researches have been conducted to explore the association of ERCC4 $\mathrm{rs} 1800067 \mathrm{~A} / \mathrm{G}$ polymorphism with susceptibility to cancer. However, the results from individual studies were inconsistent (Huang et al., 2006; Yu et al., 2012; Wang et al., 2013; Steck et al., 2014). Previous meta-analysis did not find significant association of this polymorphism with cancer risk: Ding et al. found ERCC4 rs1800067 polymorphism was not significantly associated with risk of breast cancer in 2011 (Ding et al., 2011); Shi et al. (2012) did not linked the polymorphism to altered risk of cancer in 2012.

Recently, several studies continued to explore the association of ERCC4 rs1800067 polymorphism with risk of cancer but the results were controversial (Cheng et al., 2013; Santos et al., 2013; Wang et al., 2013; Wyss et al., 2013; Kohlhase et al., 2014; Steck et al., 2014). Aiming at elucidating the exact relation between ERCC4 rs1800067 A/G polymorphism with risk of cancer, we perform the current meta-analysis by collecting the data from published case-control studies concerning the role of rs1800067 polymorphism in carcinogenesis.

\section{Materials and Methods}

\section{Identification and eligibility of relevant studies}

Literatures of electronic databases including PubMed, Web of Science, EMBASE, Wanfang and Chinese National Knowledge Infrastructure (CNKI) were systematically searched using different combinations of the search terms including "XPF/ERCC4/Xeroderma pigmentosum group $F$ ", "polymorphism/mutation/variant" and "cancer/neoplasm/malignancy". References cited in each eligible literature were further searched manually for potentially available studies. When overlapping data exists, only the largest study was adopted. The author was contacted for specific raw data if the data provided in the publications were not sufficient. The last search date was March $5^{\text {th }}, 2014$.

\section{Inclusion and exclusion criteria}

Studies included in this meta-analysis must meet the inclusion criteria as follows: case-control studies investigating the association between ERCC4 gene rs 1800067 polymorphism and risk of cancer; studies with sufficient raw data for evaluating odds ratios (OR) and their 95\% confidence interval (CI); studies published in English or Chinese. The main reasons for exclusion were no relevance; reviews or meta-analysis; duplicate publications; animal experiments; functional investigations; and not for specific polymorphisms.

\section{Data extraction}

Two authors (Quan Yuan and Jingwei Liu) independently extracted the data from the eligible studies. The following data was extracted from individual study: first author name, publication year, ethnicity of the population, type of studied cancer, the source of the control group, numbers of cases and controls and genotyping methods of ERCC4 polymorphism. The conflict was resolved after discussion and consensus was finally reached on all of the extracted information.

\section{Statistical analysis}

The statistical analysis was performed by Stata software (Version 11.0; StataCorp, College Station, TX). ORs and their corresponding 95\%CI were applied to evaluate the strength of association between ERCC4 gene rs 1800067 polymorphism and cancer risk. $P$ value $<0.05$ was considered as statistically significant. Heterogeneity was assessed by using $\mathrm{Q}$ statistic $(P<0.10$ indicates significant heterogeneity between studies) and I-squared $\left(\mathrm{I}^{2}\right)$ value (Higgins and Thompson, 2002). A fixed-effects model using Mantel-Haenszel method (Mantel and Haenszel, 1959) was performed to calculate the pooled ORs when heterogeneity between studies was not significant. Otherwise, a random-effects model using DerSimonian and Laird (1986) method was used. Sensitivity analysis was carried out to explore heterogeneity when significant heterogeneity was indicated. Subgroup analyses were performed to explore the effects of ethnicities and cancer type. In addition, publication bias was evaluated by Begg and Mazumdar (1994) test and Egger et al. (1997) test, respectively. $P$ value $<0.1$ for Begg's and Egger's tests suggests significant publication bias.

\section{Results}

\section{Study characteristics}

A total of 94 potentially relevant literatures were initially indentified through electronic databases after removing the duplicates. Sixty-four literatures were excluded after reviewing the titles and abstracts. Thirty full-text articles were further assessed for eligibility. Four publications were excluded because of meta-analysis, control group had cancer patients or not published in English. Finally, 26 full-text articles with eligibility were included in this meta-analysis (Smith et al., 2003; Huang et al., 2006; Mechanic et al., 2006; Moreno et al., 2006; Crew et al., 2007; Jorgensen et al., 2007; Chang et al., 2008; Hung et al., 2008; McWilliams et al., 2008; Rajaraman et al., 2008; Abbasi et al., 2009; Han et al., 2009; Joshi et al., 2009; Agalliu et al., 2010; Rajaraman et al., 2010; Doherty et al., 2011; Krupa et al., 2011; Smith et al., 2011; Gil et al., 2012; Yu et al., 2012; Cheng et al., 2013; Santos et al., 2013; Wang et al., 2013; Wyss et al., 2013; Kohlhase et al., 2014; Steck et al., 2014). The flow chart which reflected the details of article selection was presented in Figure 1.

The main characteristics of the studies selected in this meta-analysis were summarized in Table 1 . All the included studies were case-control designed published in English. Twenty-six articles including thirty studies (19514 cases and 20777 controls) were eventually included for meta-analysis. The types of cancer studied in relation to ERCC4 rs1800067 polymorphism covered breast cancer, colorectal cancer, thyroid cancer, head and neck cancer, glioma, laryngeal cancer, lung cancer and pancreatic cancer. The ethnicities of the included studies 
DOI:http://dx.doi.org/10.7314/APJCP.2014.15.18.7639

ERCC4 Polymorphism and Cancer Risk - an Updated Meta-analysis

Table 1. Characteristics of the Included Studies in this Meta-analysis

\begin{tabular}{|c|c|c|c|c|c|c|c|c|c|c|}
\hline \multirow[t]{2}{*}{ Author } & \multirow[t]{2}{*}{ Year } & \multirow{2}{*}{ Ethnicity } & \multirow[t]{2}{*}{ Cancer type } & \multicolumn{3}{|c|}{ Case } & \multicolumn{3}{|c|}{ Control } & \multirow[t]{2}{*}{ Genotyping method } \\
\hline & & & & AA & $\mathrm{AG}$ & GG & $\mathrm{AA}$ & $\mathrm{AG}$ & GG & \\
\hline Sandra Kohlhase & 2014 & Caucasian & Breast cancer & 18 & 403 & 3277 & 8 & 354 & 2506 & Taqman \\
\hline Susan E. Steck & 2014 & Caucasian & Colon cancer & 1 & 52 & 251 & 7 & 74 & 455 & MassArray \\
\hline Susan E. Steck & 2014 & African American & Colon cancer & 1 & 8 & 217 & 0 & 16 & 307 & MassArray \\
\hline LUÍS S. SANTOS & 2013 & Caucasian & Thyroid cancer & 2 & 23 & 77 & 4 & 38 & 168 & Taqman \\
\hline Annah B. Wyss & 2013 & $\begin{array}{c}\text { Caucasian, } \\
\text { African American }\end{array}$ & $\begin{array}{l}\text { Head and } \\
\text { Neck cancer }\end{array}$ & 144 & & 778 & 154 & & 920 & Illumina \\
\hline Hong-Bin Cheng & 2013 & Asian & Glioma & 149 & 41 & 17 & 182 & 43 & 11 & MassArray \\
\hline Xue-Feng Wang & 2013 & Asian & Glioma & 265 & 59 & 6 & 609 & 36 & 7 & MassArray \\
\hline Hongping Yu & 2012 & Caucasian & Head and Neck cancer & 8 & 195 & 837 & 8 & 209 & 829 & SNPlex \\
\hline Justyna Gil & 2012 & Caucasian & Colorectal cancer & 0 & 14 & 119 & 0 & 15 & 83 & PCR-RFLP \\
\hline R. Krupa & 2011 & Caucasian & Larynx cancer & 6 & 26 & 221 & 0 & 29 & 224 & PCR-RFLP \\
\hline Jennifer A. Doherty & 2011 & Caucasian & Endometrial cancer & 3 & 107 & 593 & 5 & 89 & 620 & SNPlex, Taqman \\
\hline Preetha Rajaraman & 2010 & Caucasian & Glioma etc. & 3 & 89 & 434 & 4 & 62 & 405 & Q-PCR \\
\hline Ilir Agalliu & 2010 & Caucasian & Prostate cancer & 13 & 183 & 1025 & 5 & 202 & 1012 & SNPlex \\
\hline Ilir Agalliu & 2010 & African American & Prostate cancer & 0 & 8 & 136 & 0 & 3 & 78 & SNPlex \\
\hline Amit D.Joshi & 2009 & Caucasian & Colorectal cancer & 40 & & 265 & 47 & & 313 & Q-PCR \\
\hline Jiali Han & 2009 & Caucasian & Breast cancer & 0 & 38 & 200 & 2 & 69 & 401 & BeadArray \\
\hline Rashda Abbasi & 2009 & Caucasian & Laryngeal cancer & 1 & 44 & 203 & 3 & 90 & 554 & Q-PCR \\
\hline Tasha R.Smith & 2008 & Caucasian & Breast cancer & 7 & 39 & 278 & 1 & 47 & 358 & MassArray \\
\hline Tasha R.Smith & 2008 & African American & Breast cancer & 0 & 2 & 51 & 0 & 2 & 73 & MassArray \\
\hline Preetha Rajaraman & 2008 & Caucasian & Breast cancer & 124 & & 714 & 147 & & 922 & Q-PCR \\
\hline Robert R. McWilliams & 2008 & Caucasian & Pancreatic cancer & 0 & 59 & 411 & 4 & 111 & 481 & SNPstream, Sequencing \\
\hline Rayjean J. Hung & 2008 & Caucasian,Asia & Lung cancer & 13 & 306 & 2201 & 21 & 390 & 2208 & Pooled \\
\hline Jeffrey S. Chang & 2008 & Latino & Lung cancer & 0 & 16 & 97 & 1 & 31 & 267 & BeadArray \\
\hline T. J. Jorgensen & 2007 & Caucasian & Breast cancer & 1 & 37 & 221 & 1 & 43 & 231 & Q-PCR \\
\hline Katherine D. Crew & 2007 & Caucasian & Breast cancer & 3 & 156 & 859 & 10 & 167 & 888 & Q-PCR, Sequenom \\
\hline Victor Moreno & 2006 & Caucasian & Colorectal cancer & 7 & 71 & 282 & 5 & 61 & 257 & APEX microarray \\
\hline Leah E.Mechanic & 2006 & African American & Breast cancer & 1 & 18 & 738 & 0 & 31 & 642 & Q-PCR, Sequencing \\
\hline Leah E.Mechanic & 2006 & Caucasian & Breast cancer & 12 & 185 & 1049 & 3 & 150 & 980 & Q-PCR, Sequencing \\
\hline Wen-Yi Huang & 2006 & Mixed & Colorectal cancer & 1 & 78 & 624 & 7 & 86 & 623 & Pooled \\
\hline Tasha R. Smith & 2003 & Caucasian & Breast cancer & 7 & 29 & 217 & 0 & 32 & 236 & PCR-RFLP \\
\hline
\end{tabular}

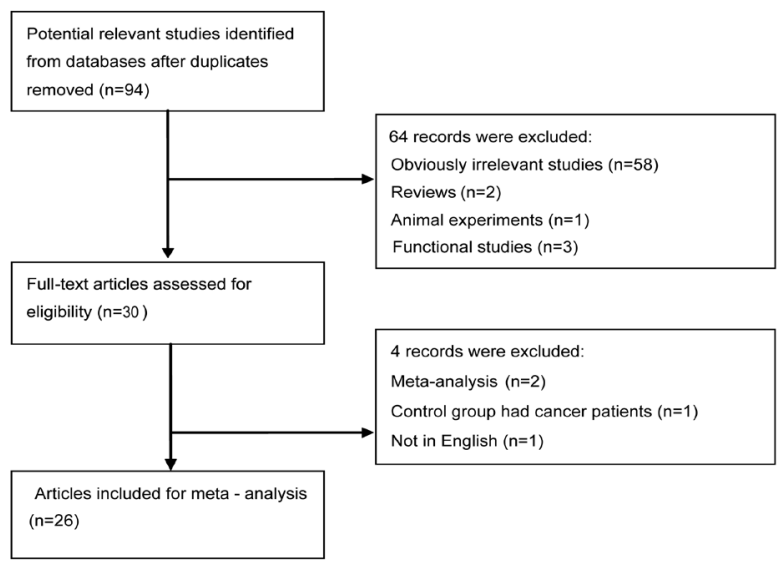

Figure 1. The Flowchart of Literature Inclusion and Exclusion

had Caucasian, Asian, African American and Latino.

\section{Quantitative data synthesis}

Results of the association between ERCC4 rs 1800067 A/G polymorphism and cancer risk was summarized in Table 2. There was no significant association between ERCC4 rs1800067 AA or AG genotypes and overall risk of cancer (AA vs. GG: $\mathrm{OR}=0.998,95 \% \mathrm{CI}=0.670$ 1.486, $P=0.992$; AG vs. GG: $\mathrm{OR}=0.970,95 \% \mathrm{CI}=0.888$ 1.061, $P=0.508)$. Dominant genetic model also did not demonstrate significant association of $(\mathrm{AA}+\mathrm{AG})$ genotype carriers with altered risk of overall cancer compared with GG genotype carriers $(\mathrm{OR}=0.985,95 \% \mathrm{CI}=0.909-1.068$, $P=0.719$, Figure 2). In addition, no significant association was observed between A allele of ERCC4 rs 1800067 A/G

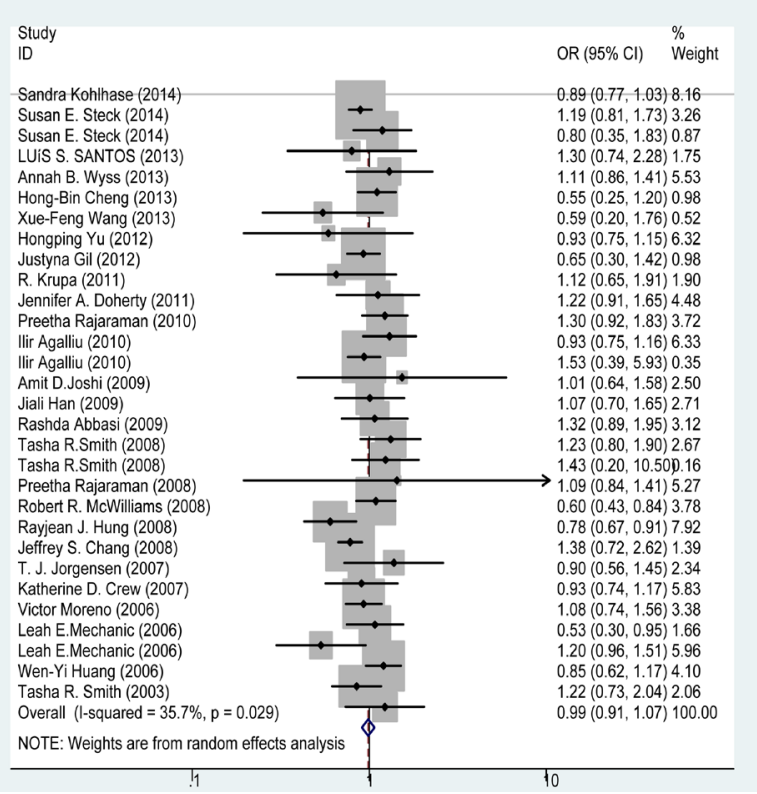

Figure 2. Forest Plot for the Association between ERCC4 rs1800067 A/G Polymorphism and Cancer Risk ((AA+AG) vs. GG)

polymorphism and altered cancer risk compared with $\mathrm{G}$ allele $(\mathrm{OR}=0.952,95 \% \mathrm{CI}=0.851-1.063, P=0.381$, Figure 3).

Subgroup analysis was then performed to explore the effect of different ethnicities and cancer types. For different subgroups of ethnicities, no significant association was found between ERCC4 rs 1800067 $\mathrm{A} / \mathrm{G}$ polymorphism and altered cancer risk (Table 2). 
Table 2. Association between ERCC4 rs1800067 Polymorphism and Cancer Risk

\begin{tabular}{|c|c|c|c|c|c|c|c|}
\hline \multirow[t]{2}{*}{ Genetic model } & \multirow[t]{2}{*}{ Group/Subgroup } & \multirow[t]{2}{*}{ No. } & \multicolumn{2}{|c|}{ Heterogeneity Test } & \multirow[t]{2}{*}{ Statistical model } & \multicolumn{2}{|c|}{ Test for overall effect } \\
\hline & & & $\mathrm{I}^{2}(\%)$ & $P_{\text {het }}$ & & OR $(95 \% \mathrm{CI})$ & $P$ \\
\hline \multirow[t]{7}{*}{$\overline{\text { AA vs. GG }}$} & Overall & 27 & $39.00 \%$ & 0.027 & $\mathrm{R}$ & $0.998(0.670-1.486)$ & 0.992 \\
\hline & Colorectal & 4 & $45.00 \%$ & 0.141 & $\mathrm{~F}$ & $0.606(0.281-1.308)$ & 0.202 \\
\hline & Breast & 8 & $50.00 \%$ & 0.051 & $\mathrm{R}$ & $1.853(0.747-4.596)$ & 0.183 \\
\hline & Lung & 2 & $0.00 \%$ & 0.817 & $\mathrm{~F}$ & $0.632(0.320-1.246)$ & 0.185 \\
\hline & Glioma & 2 & $0.00 \%$ & 0.951 & $\mathrm{~F}$ & $0.523(0.275-0.993)$ & 0.048 \\
\hline & Caucasian & 17 & $37.30 \%$ & 0.061 & $\mathrm{R}$ & $1.266(0.777-2.062)$ & 0.344 \\
\hline & African American & 2 & $0.00 \%$ & 0.834 & $\mathrm{~F}$ & $3.321 \quad(0.345-32.018)$ & 0.299 \\
\hline \multirow[t]{7}{*}{ AG vs. GG } & Overall & 27 & $35.00 \%$ & 0.039 & $\mathrm{R}$ & $0.970(0.888-1.061)$ & 0.508 \\
\hline & Colorectal & 5 & $0.00 \%$ & 0.444 & $\mathrm{~F}$ & $0.995(0.818-1.211)$ & 0.962 \\
\hline & Breast & 9 & $13.90 \%$ & 0.318 & $\mathrm{~F}$ & $0.946(0.857-1.045)$ & 0.275 \\
\hline & Lung & 2 & $66.90 \%$ & 0.082 & $\mathrm{R}$ & $0.970(0.558-1.687)$ & 0.914 \\
\hline & Glioma & 2 & $56.90 \%$ & 0.128 & $\mathrm{~F}$ & $0.921 \quad(0.464-1.828)$ & 0.813 \\
\hline & Caucasian & 18 & $30.70 \%$ & 0.106 & $\mathrm{~F}$ & $0.983(0.915-1.056)$ & 0.635 \\
\hline & African American & 4 & $0.00 \%$ & 0.412 & $\mathrm{~F}$ & $0.660(0.426-1.024)$ & 0.064 \\
\hline \multirow[t]{8}{*}{$(\mathrm{AA}+\mathrm{AG})$ vs. GG } & Overall & 30 & $35.70 \%$ & 0.029 & $\mathrm{R}$ & $0.985(0.909-1.068)$ & 0.719 \\
\hline & Colorectal & 6 & $0.00 \%$ & 0.652 & $\mathrm{~F}$ & $0.972(0.815-1.160)$ & 0.753 \\
\hline & Breast & 10 & $25.00 \%$ & 0.214 & $\mathrm{~F}$ & $0.985(0.899-1.080)$ & 0.752 \\
\hline & Lung & 2 & $64.80 \%$ & 0.092 & $\mathrm{R}$ & $0.947(0.557-1.610)$ & 0.841 \\
\hline & Glioma & 2 & $0.00 \%$ & 0.919 & $\mathrm{~F}$ & $0.559(0.296-1.057)$ & 0.073 \\
\hline & Head and Neck & 2 & $11.20 \%$ & 0.288 & $\mathrm{~F}$ & $1.000(0.850-1.175)$ & 0.997 \\
\hline & Caucasian & 20 & $26.90 \%$ & 0.131 & $\mathrm{~F}$ & $1.004(0.939-1.073)$ & 0.908 \\
\hline & African American & 4 & $0.00 \%$ & 0.439 & $\mathrm{~F}$ & $0.701(0.455-1.079)$ & 0.107 \\
\hline \multirow[t]{7}{*}{ A allele vs. G allele } & Overall & 27 & $66.40 \%$ & 0.000 & $\mathrm{R}$ & $0.952(0.851-1.063)$ & 0.381 \\
\hline & Colorectal & 5 & $0.00 \%$ & 0.528 & $\mathrm{~F}$ & $0.942(0.787-1.127)$ & 0.511 \\
\hline & Breast & 9 & $47.70 \%$ & 0.054 & $\mathrm{R}$ & $1.025(0.879-1.195)$ & 0.753 \\
\hline & Lung & 2 & $59.40 \%$ & 0.117 & $\mathrm{~F}$ & $0.806 \quad(0.697-0.931)$ & 0.003 \\
\hline & Glioma & 2 & $88.40 \%$ & 0.003 & $\mathrm{R}$ & $0.489(0.228-1.052)$ & 0.067 \\
\hline & Caucasian & 17 & $41.40 \%$ & 0.034 & $\mathrm{R}$ & $1.039(0.945-1.141)$ & 0.431 \\
\hline & African American & 4 & $0.00 \%$ & 0.465 & $\mathrm{~F}$ & $0.747(0.491-1.138)$ & 0.175 \\
\hline
\end{tabular}

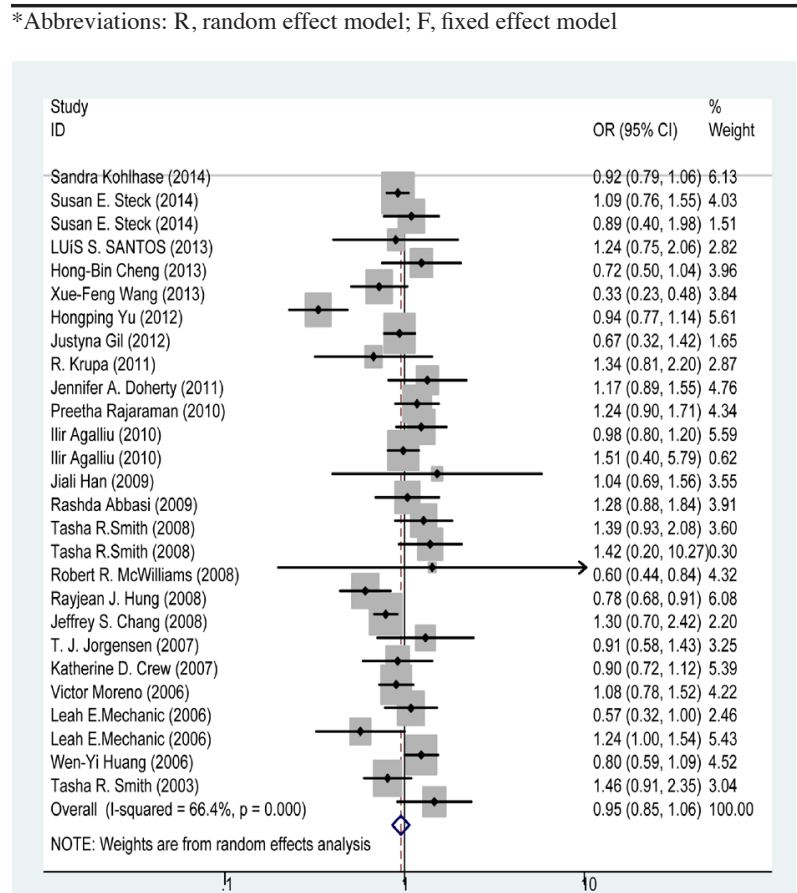

Figure 3. Forest Plot for the Association between ERCC4 rs1800067 A/G Polymorphism and Cancer Risk (A allele vs. G allele)

For subgroup of glioma, AA genotype carriers were observed to be significantly associated with decreased risk of glioma compared with wild-type GG genotype individuals $(\mathrm{OR}=0.523,95 \% \mathrm{CI}=0.275-0.993, P=0.048)$. For subgroup of lung cancer, A allele of ERCC4 rs 1800067 A/G polymorphism was significantly associated with decreased risk of lung cancer compared with $\mathrm{G}$ allele (OR=0.806, 95\% CI=0.697-0.931, $P=0.003)$.

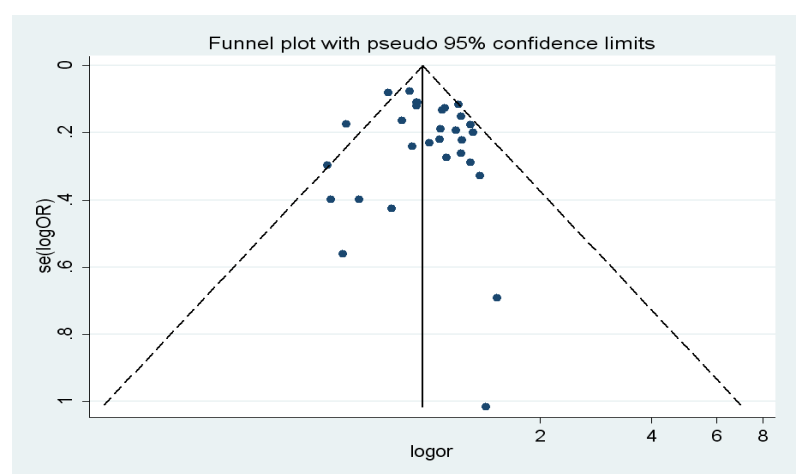

Figure 4. Funnel Plot for Studies of Association between ERCC4 rs1800067 A/G Polymorphism and Cancer Risk ((AA+AG) vs. GG)

Heterogeneity test, sensitivity analysis and publication bias

In some comparisons of ERCC4 rs $1800067 \mathrm{~A} / \mathrm{G}$ polymorphism and cancer risk, significant heterogeneities were observed where random effect model was used. Subgroup analysis reduced the heterogeneities in some genetic models (Table 2). We therefore performed sensitivity analysis to detect the influence of individual study on the pooled estimate by omitting one study from the pooled analysis each time. The outcomes suggested that no individual study significantly affected the pooled OR (figure not shown), indicating that the results of the meta-analysis were robust.

The Begg's test and Egger's test were conducted to quantitatively assess the publication bias of the included studies. The detailed information for publication bias test was shown in Table 3 . No significant publication bias 
Table 3. Publication Bias

\begin{tabular}{lcccc}
\hline Compared genotype & \multicolumn{2}{c}{ Begg's test } & \multicolumn{2}{c}{ Egger's test } \\
& z value & P value & t value & P value \\
\hline AA vs. GG & 0.15 & 0.884 & 1.30 & 0.206 \\
AG vs. GG & 0.69 & 0.487 & 0.80 & 0.431 \\
(AA+AG) vs. GG & -0.45 & 0.656 & 0.89 & 0.383 \\
A allele vs. G allele & 0.15 & 0.884 & 0.66 & 0.517 \\
\hline
\end{tabular}

was observed in the present meta-analysis. Besides, the funnel plot which reflects the studies of the association of $(\mathrm{AA}+\mathrm{AG})$ genotype with cancer risk was presented in Figure 4.

\section{Discussion}

As a key member of NER system, ERCC4 polymorphism might be related to cancer susceptibilities. The relation of DNA repair gene polymorphism and cancer risk has been widely studies (Li et al., 2013; Yang et al., 2013). Previous studies concerning the association between ERCC4 rs 1800067 A/G polymorphism and risk of cancer were controversial. By conducting the present meta-analysis, we suggested that ERCC4 rs1800067 A/G polymorphism might not be associated with risk of overall cancer. However, individuals with AA genotype were associated with significantly reduced risk of glioma compared with wild-type GG genotype; A allele was associated with significantly reduced risk of lung cancer.

Human ERCC4 gene, also named as XPF, is located at chromosome $6 \mathrm{p} 13.12$, consisting of eleven exons and ten introns. ERCC4 exert its functions in the irreversible dual-incision process during NER by forming an obligate heterodimer complex with ERCC1 and then operating 5' incision to the DNA lesion (Nouspikel, 2009). More importantly, the catalyzing domain that determines NER activity is in ERCC4 (Enzlin and Scharer, 2002). Additionally, low expression of ERCC4 has been reported to be related with an elevated risk of head and neck cancer (Wei et al., 2005). Key polymorphism of ERCC4 might affect the expression and function of ERCC4 protein and its role in NER system, thus altering individual's susceptibility to cancer. Driven by this hypothesis, an increasing number of studies investigated the association between ERCC4 rs 1800067 A/G polymorphism and risk of cancer in recent years. However, the results from individual studies were inconclusive.

By collecting and analyzing the data from published twenty-six articles including thirty studies conducted on the association of ERCC4 rs 1800067 polymorphism with cancer risk, we found that ERCC4 rs1800067 AA or AG genotypes was not significantly associated with overall risk of cancer (AA vs. GG: OR=0.998, $P=0.992$; AG vs. GG: $\mathrm{OR}=0.970, P=0.508)$. Dominant genetic model also did not demonstrate significant association of (AA+AG) genotype carriers with altered risk of overall cancer compared with $\mathrm{GG}$ genotype carriers $(\mathrm{OR}=0.985$, $P=0.719$ ). In addition, no significant association was observed between A allele of ERCC4 rs1800067 A/G polymorphism and altered cancer risk compared with $G$ allele $(\mathrm{OR}=0.952, P=0.381)$, indicating that this polymorphism might not be associated with overall risk of cancer. Subgroup analysis found that individuals with AA genotype were associated with significantly reduced risk of glioma compared with wild-type GG genotype; A allele was associated with significantly reduced risk of lung cancer, suggesting that ERCC4 rs1800067 A/G polymorphism might be involved in the carcinogenesis of glioma and lung cancer. Considering the limited number of studies for certain subgroups, future large-scale investigations are still needed to draw a more reliable conclusion.

Our meta-analysis had advantages than the previously published meta-analysis conducted on the association of ERCC4 rs1800067 polymorphism and cancer risk. This meta-analysis included all types of cancer into pooled analysis, while the Ding et al. (2011) meta-analysis only investigated breast cancer susceptibility. In addition, Shi et al. (2012) meta-analysis did not find significant association of ERCC4 rs1800067 polymorphism with risk of overall cancer or in any subgroup. In the present meta-analysis, we included twenty-six articles including thirty studies (19514 cases and 20777 controls) and revealed significant association between ERCC4 rs1800067 polymorphism and certain cancer subtypes.

Several limitations should also be acknowledged in the present meta-analysis. First, the studied sample was relatively not large for certain subgroup analysis. Second, obvious heterogeneity was observed in the comparisons of ERCC4 rs1800067 A/G polymorphism and risk of cancer, which could not be fully explained by subgroup analysis. Third, the ethnicities of all the included studies were mainly Caucasians, which may limit the generalizability of our conclusion. Fourth, other important raw data such as age, sex and family history were not available for each individual study so that we could not obtain results with adjustments by other co-variables.

In conclusion, to be concluded, this meta-analysis indicated that ERCC4 rs1800067 A/G polymorphism might not be associated with risk of overall cancer. However, individuals with AA genotype were associated with significantly reduced risk of glioma compared with wild-type GG genotype; A allele was associated with significantly reduced risk of lung cancer compared with $\mathrm{G}$ allele. Future large-scale studies performed in multiple populations are warranted to confirm our results.

\section{Acknowledgements}

This study was supported by grants from National Basic Research Program of China (973 Program Ref No.2010CB529304), the grants of the Science and Technology Project of Liaoning province (Ref No.2012225016).

\section{References}

Abbasi R, Ramroth H, Becher H, et al (2009). Laryngeal cancer risk associated with smoking and alcohol consumption is modified by genetic polymorphisms in ERCC5, ERCC6 and RAD23B but not by polymorphisms in five other nucleotide excision repair genes. Int J Cancer, 125, 1431-9.

Agalliu I, Kwon EM, Salinas CA, et al (2010). Genetic variation 
in DNA repair genes and prostate cancer risk: results from a population-based study. Cancer Causes Control, 21, 289-300.

Begg CB, Mazumdar M (1994). Operating characteristics of a rank correlation test for publication bias. Biometrics, 50, 1088-101.

Chang JS, Wrensch MR, Hansen HM, et al (2008). Nucleotide excision repair genes and risk of lung cancer among San Francisco Bay Area Latinos and African Americans. Int $J$ Cancer, 123, 2095-104.

Cheng HB, Xie C, Zhang RY, et al (2013). Xeroderma pigmentosum complementation group $\mathrm{F}$ polymorphisms influence risk of glioma. Asian Pac J Cancer Prev, 14, 4083-7.

Crew KD, Gammon MD, Terry MB, et al (2007). Polymorphisms in nucleotide excision repair genes, polycyclic aromatic hydrocarbon-DNA adducts, and breast cancer risk. Cancer Epidemiol Biomarkers Prev, 16, 2033-41.

de Laat WL, Jaspers NG, Hoeijmakers JH (1999). Molecular mechanism of nucleotide excision repair. Genes Dev, 13, 768-85.

DerSimonian R, Laird N (1986). Meta-analysis in clinical trials. Control Clin Trials, 7, 177-88.

Ding DP, He XF, Zhang Y (2011). Lack of association between XPG Asp1104His and XPF Arg415Gln polymorphism and breast cancer risk: a meta-analysis of case-control studies. Breast Cancer Res Treat, 129, 203-9.

Doherty JA, Weiss NS, Fish S, et al (2011). Polymorphisms in nucleotide excision repair genes and endometrial cancer risk. Cancer Epidemiol Biomarkers Prev, 20, 1873-82.

Egger M, Davey Smith G, Schneider M, et al (1997). Bias in meta-analysis detected by a simple, graphical test. $B M J, \mathbf{3 1 5}$, 629-34.

Enzlin JH, Scharer OD (2002). The active site of the DNA repair endonuclease XPF-ERCC1 forms a highly conserved nuclease motif. EMBO J, 21, 2045-53.

Fagbemi AF, Orelli B, Scharer OD (2011). Regulation of endonuclease activity in human nucleotide excision repair. DNA Repair, 10, 722-9.

Friedberg EC (2001). How nucleotide excision repair protects against cancer. Nat Rev Cancer, 1, 22-33.

Gil J, Ramsey D, Stembalska A, et al (2012). The C/A polymorphism in intron 11 of the XPC gene plays a crucial role in the modulation of an individual's susceptibility to sporadic colorectal cancer. Mol Biol Rep, 39, 527-34.

Han J, Haiman C, Niu T, et al (2009). Genetic variation in DNA repair pathway genes and premenopausal breast cancer risk. Breast Cancer Res Treat, 115, 613-22.

Higgins JP, Thompson SG (2002). Quantifying heterogeneity in a meta-analysis. Stat Med, 21, 1539-58.

Huang WY, Berndt SI, Kang D, et al (2006). Nucleotide excision repair gene polymorphisms and risk of advanced colorectal adenoma: XPC polymorphisms modify smoking-related risk. Cancer Epidemiol Biomarkers Prev, 15, 306-11.

Hung RJ, Christiani DC, Risch A, et al (2008). International lung cancer consortium: pooled analysis of sequence variants in DNA repair and cell cycle pathways. Cancer Epidemiol Biomarkers Prev, 17, 3081-9.

Jorgensen TJ, Visvanathan K, Ruczinski I, et al (2007). Breast cancer risk is not associated with polymorphic forms of xeroderma pigmentosum genes in a cohort of women from Washington County, Maryland. Breast Cancer Res Treat, 101, 65-71.

Joshi AD, Corral R, Siegmund KD, et al (2009). Red meat and poultry intake, polymorphisms in the nucleotide excision repair and mismatch repair pathways and colorectal cancer risk. Carcinogenesis, 30, 472-9.

Kohlhase S, Bogdanova NV, Schurmann P, et al (2014). Mutation analysis of the ERCC4/FANCQ gene in hereditary breast cancer. PLoS One, 9, e85334.

Krupa R, Kasznicki J, Gajecka M, et al (2011). Polymorphisms of the DNA repair genes XRCC1 and ERCC4 are not associated with smoking- and drinking-dependent larynx cancer in a Polish population. Exp Oncol, 33, 55-6.

Li Q, Wang JM, Peng Y, et al (2013). Association of DNA baseexcision repair XRCC1, OGG1 and APE1 gene polymorphisms with nasopharyngeal carcinoma susceptibility in a Chinese population. Asian Pac J Cancer Prev, 14, 5145-51.

Lindahl T, Wood RD (1999). Quality control by DNA repair. Science, 286, 1897-905.

Mantel N, Haenszel W (1959). Statistical aspects of the analysis of data from retrospective studies of disease. J Natl Cancer Inst, 22, 719-48.

McWilliams RR, Bamlet WR, Cunningham JM, et al (2008). Polymorphisms in DNA repair genes, smoking, and pancreatic adenocarcinoma risk. Cancer Res, 68, 4928-35.

Mechanic LE, Millikan RC, Player J, et al (2006). Polymorphisms in nucleotide excision repair genes, smoking and breast cancer in African Americans and whites: a population-based casecontrol study. Carcinogenesis, 27, 1377-85.

Moreno V, Gemignani F, Landi S, et al (2006). Polymorphisms in genes of nucleotide and base excision repair: risk and prognosis of colorectal cancer. Clin Cancer Res, 12, 2101-8.

Niedernhofer LJ, Odijk H, Budzowska M, et al (2004). The structure-specific endonuclease Ercc1-Xpf is required to resolve DNA interstrand cross-link-induced double-strand breaks. Mol Cell Biol, 24, 5776-87.

Nouspikel T (2009). DNA repair in mammalian cells : Nucleotide excision repair: variations on versatility. Cell Mol Life Sci, 66, 994-1009.

Rajaraman P, Bhatti P, Doody MM, et al (2008). Nucleotide excision repair polymorphisms may modify ionizing radiationrelated breast cancer risk in US radiologic technologists. Int J Cancer, 123, 2713-6.

Rajaraman P, Hutchinson A, Wichner S, et al (2010). DNA repair gene polymorphisms and risk of adult meningioma, glioma, and acoustic neuroma. Neuro Oncol, 12, 37-48.

Santos LS, Gomes BC, Gouveia R, et al (2013). The role of CCNH Val270Ala (rs2230641) and other nucleotide excision repair polymorphisms in individual susceptibility to welldifferentiated thyroid cancer. Oncol Rep, 30, 2458-66.

Shi TY, He J, Qiu LX, et al (2012). Association between XPF polymorphisms and cancer risk: a meta-analysis. PLoS One, 7, e38606.

Smith TR, Levine EA, Perrier ND, et al (2003). DNA-repair genetic polymorphisms and breast cancer risk. Cancer Epidemiol Biomarkers Prev, 12, 1200-4.

Smith TR, Liu-Mares W, Van Emburgh BO, et al (2011). Genetic polymorphisms of multiple DNA repair pathways impact age at diagnosis and TP53 mutations in breast cancer. Carcinogenesis, 32, 1354-60.

Steck SE, Butler LM, Keku T, et al (2014). Nucleotide excision repair gene polymorphisms, meat intake and colon cancer risk. Mutat Res Fundam Mol Mech Mutagen, 762, 24-31.

Wang XF, Liu S, Shao ZK (2013). Effects of polymorphisms in nucleotide excision repair genes on glioma risk in a Chinese population. Gene, 529, 317-20.

Wei Q, Wang LE, Sturgis EM, et al (2005). Expression of nucleotide excision repair proteins in lymphocytes as a marker of susceptibility to squamous cell carcinomas of the head and neck. Cancer Epidemiol Biomarkers Prev, 14, 1961-6.

Wyss AB, Herring AH, Avery CL, et al (2013). Single-nucleotide polymorphisms in nucleotide excision repair genes, cigarette smoking, and the risk of head and neck cancer. Cancer Epidemiol Biomarkers Prev, 22, 1428-45.

Yang B, Chen WH, Wen XF, et al (2013). Role of DNA repairrelated gene polymorphisms in susceptibility to risk of prostate cancer. Asian Pac J Cancer Prev, 14, 5839-42.

Yu H, Liu Z, Huang YJ, et al (2012). Association between single nucleotide polymorphisms in ERCC4 and risk of squamous cell carcinoma of the head and neck. PLoS One, 7, e41853. 